\title{
A novel reactor configuration for packed bed chemical-looping combustion of syngas
}

\author{
H.P. Hamers (TU/e) \\ F. Gallucci (TU/e) \\ P.D. Cobden (ECN) \\ E. Kimball (TNO)
}

M. van Sint Annaland (TU/e)

April 2013

ECN-W--13-013 


\title{
A novel reactor configuration for packed bed chemical-looping combustion of syngas
}

\author{
H.P. Hamers ${ }^{\text {a }}$, F. Gallucci a , P.D. Cobden ${ }^{\text {b }}$, E. Kimball ${ }^{\text {c }}$, M. van Sint Annaland ${ }^{\text {a,* }}$ \\ a Multiphase Reactor Group, Chemical Process Intensification, Department of Chemical Engineering and Chemistry, Eindhoven University of Technology, \\ P.O. Box 513, 5600 MB Eindhoven, The Netherlands \\ ${ }^{\mathrm{b}}$ Energy Research Centre of the Netherlands (ECN), P.O. Box 1, 1755 ZG Petten, The Netherlands \\ ${ }^{c}$ TNO Gas Treatment, P.O. Box 6000, 2600 JA Delft, The Netherlands
}

\section{A R T I C L E I N F O}

\section{Article history:}

Received 22 December 2012

Received in revised form 20 February 2013

Accepted 21 February 2013

\section{Keywords:}

Chemical-looping combustion

Packed beds

Syngas

$\mathrm{CO}_{2}$ capture

Power production

Two-stage CLC

\begin{abstract}
A B S T R A C T
This study reports on the application of chemical looping combustion (CLC) in pressurized packed bed reactors using syngas as a fuel. High pressure operation of CLC in packed bed has a different set of challenges in terms of material properties, cycle and reactor design compared to fluidized bed operation. However, high pressure operation allows the use of inherently more efficient power cycles than low pressure fluidized bed solutions. This paper quantifies the challenges in high pressure operation and introduces a novel reactor concept with which those challenges can be addressed. Continuous cyclic operation of a packed bed CLC system is simulated in a 1D numerical reactor model. Importantly, it is demonstrated that the temperature profiles that can occur in a packed bed reactor as a result of the different process steps do not accumulate, and have a negligible effect on the overall performance of the system. Moreover, it has been shown that an even higher energy efficiency can be achieved by feeding the syngas from the opposite direction during the reduction step (i.e. countercurrent operation). Unfortunately, in this configuration mode, more severe temperature fluctuations occur in the reactor exhaust, which is disadvantageous for the operation of a downstream gas turbine. Finally, a novel reactor configuration is introduced in which the desired temperature rise for obtained hot pressured air suitable for a gas turbine is obtained by carrying out the process with two packed bed reactor in series (twostage (LC). This is shown to be a good alternative to the single bed configuration, and has the added advantage of decreasing the demands on both the oxygen carrier and the reactor materials and design specification.
\end{abstract}

(c) 2013 Elsevier Ltd. All rights reserved.

\section{Introduction}

Due to climate concerns caused by anthropogenic greenhouse gas emissions, much research is carried out toward reducing the $\mathrm{CO}_{2}$ emissions. Among the various strategies proposed, carbon capture and sequestration (CCS) has been advocated to be a good candidate for $\mathrm{CO}_{2}$ emissions mitigation. CCS has to be regarded as a mid-term solution as long as the energy economy is based on fossil fuels: i.e. CCS is necessary as long as other technologies such as large scale exploitation of renewable sources and nuclear fusion are still under development and more expensive (IPCC, 2005). CCS consists of two challenging processes, i.e. carbon dioxide capture and its sequestration (mineralization or storage). Currently, the $\mathrm{CO}_{2}$ capture step is considered to be the most energy intensive step in CCS. In most $\mathrm{CO}_{2}$ capture technologies, an energy intensive physical gas separation has to be carried out (for post-combustion capture,

\footnotetext{
* Corresponding author. Tel.: +31 40247 2241; fax: +31 402475833 .

E-mail address: M.v.SintAnnaland@tue.nl (M. van Sint Annaland).
}

$\mathrm{CO}_{2} / \mathrm{N}_{2}$ separation is required; for pre-combustion, $\mathrm{CO}_{2} / \mathrm{H}_{2}$; and for oxyfuel-combustion, $\mathrm{O}_{2} / \mathrm{N}_{2}$ ). One interesting novel capture route, which is gaining increased interest within the scientific community, is chemical-looping combustion (CLC), a process that could be regarded as a special case within possible oxyfuel processes.

With CLC, electricity generation with inherent $\mathrm{CO}_{2}$ capture can be carried out efficiently, because direct contact between the fuel and air is avoided by carrying out the reactions in two different steps. First, the fuel reacts with an intermediate solid oxygen carrier, producing $\mathrm{CO}_{2}$ and $\mathrm{H}_{2} \mathrm{O}$. In the second step, the carrier is oxidized again during reaction with air. So, oxygen is transferred from the air to the fuel via the oxygen carrier. The method used to transfer the oxygen between the air and fuel, depends on the reactor configuration. In most CLC studies, the oxygen carrier solid is physically transferred between dual circulating fluidized bed reactors. This concept has been demonstrated in several experimental units (Linderholm et al., 2008; Lyngfelt, 2011b; Forero et al., 2009; Kolbitsch et al., 2010). Another possibility is alternating the gas feed in a dynamically operated packed bed reactor. The selection between the two configurations strongly depends on the desired 


\begin{tabular}{|c|c|}
\hline \multicolumn{2}{|c|}{ Nomenclature } \\
\hline \multicolumn{2}{|c|}{ Abbreviations } \\
\hline CLC & chemical-looping combustion \\
\hline \multicolumn{2}{|c|}{ Symbols } \\
\hline$c$ & concentration $\left(\mathrm{mol} \mathrm{m}^{-3}\right)$ \\
\hline$C_{p}$ & heat capacity $\left(\mathrm{J} \mathrm{mol}^{-1} \mathrm{~K}^{-1}\right)$ \\
\hline$D_{\mathrm{ax}}$ & axial dispersion coefficient $\left(\mathrm{m}^{2} \mathrm{~s}^{-1}\right)$ \\
\hline$d_{p}$ & particle diameter $(\mathrm{m})$ \\
\hline$\Delta H_{R}$ & enthalpy of reaction $\left(\mathrm{J} \mathrm{mol}^{-1}\right)$ \\
\hline$k$ & reaction rate constant $\left(\mathrm{s}^{-1}\right)$ \\
\hline$L$ & length of the reactor $(\mathrm{m})$ \\
\hline$M$ & molar mass $(\mathrm{kg} / \mathrm{mol})$ \\
\hline$n$ & reaction order in gas \\
\hline $\mathrm{Nu}$ & Nusselt number \\
\hline $\operatorname{Pr}$ & Prandtl number \\
\hline$r$ & reaction rate $\left(\mathrm{mol} \mathrm{m}^{-3} \mathrm{~s}^{-1}\right)$ \\
\hline $\operatorname{Re}$ & Reynolds number \\
\hline Sc & Schmidt number \\
\hline$T$ & temperature (K) \\
\hline$t$ & time $(s)$ \\
\hline$v$ & velocity $\left(\mathrm{m} \mathrm{s}^{-1}\right)$ \\
\hline$x$ & axial position $(\mathrm{m})$ \\
\hline$w_{h}$ & heat front velocity $\left(\mathrm{m} \mathrm{s}^{-1}\right)$ \\
\hline$w_{r}$ & reaction front velocity $\left(\mathrm{m} \mathrm{s}^{-1}\right)$ \\
\hline \multicolumn{2}{|c|}{ Greek letters } \\
\hline$\varepsilon$ & porosity $\left(\mathrm{m}^{3} / \mathrm{m}^{3}\right)$ \\
\hline$\zeta$ & stoichiometric factor (mol gas/mol solid) \\
\hline$\lambda$ & effective heat dispersion coefficient $\left(\mathrm{W} \mathrm{m}^{-1} \mathrm{~K}^{-1}\right)$ \\
\hline$\omega$ & mass fraction $(\mathrm{kg} / \mathrm{kg})$ \\
\hline \multicolumn{2}{|c|}{ subscripts } \\
\hline$s$ & solid \\
\hline$g$ & gas \\
\hline act & active \\
\hline$i$ & gas component \\
\hline$j$ & solid component \\
\hline eff & effective \\
\hline \multicolumn{2}{|c|}{ superscripts } \\
\hline in & inlet \\
\hline$o$ & in oxidized state \\
\hline
\end{tabular}

operating conditions and fuel type. Theoretically, an electrical efficiency of almost $53 \%$ could be achieved in a configuration where high pressure gas (above 20 bar) could be provided to a gas turbine at an inlet temperature of $1200^{\circ} \mathrm{C}$ (Wolf et al., 2005).

As large reserves of solid fuels are still available, several ways for converting solids in the chemical-looping concept are under investigation, like direct feeding of solids in a CLC system or the chemical-looping oxygen uncoupling (CLOU) process. Direct feeding of solids in the reactor shows additional challenges such as (i) much slower kinetics compared with gaseous fuels and (ii) requirement of an additional carbon stripper and oxygen polisher. In the CLOU process, oxygen carriers are selected that release oxygen, which combusts the solid fuel. The achieved temperature in the air reactor in CLOU is dependent on the thermodynamics of the carrier pairs $\left(\mathrm{CuO} / \mathrm{Cu}_{2} \mathrm{O}, \mathrm{Mn}_{2} \mathrm{O}_{3} / \mathrm{Mn}_{3} \mathrm{O}_{4}\right.$, and $\left.\mathrm{Co}_{3} \mathrm{O}_{4} / \mathrm{CoO}\right)$. With these pairs, it is not possible to produce air at $1200^{\circ} \mathrm{C}$ (Mattisson et al., 2009). An alternative to process solids is the combination of solid gasification (which is a standard technology) followed by chemicallooping combustion of the produced syngas. The process discussed in this paper is thus the chemical-looping combustion of syngas derived by solid fuel gasification (where the solid fuel could consist of coal or biomass).

Under operating conditions needed to obtain a highly energy efficient gas turbine cycle, a circulating fluidized bed system encounters some difficult challenges. Especially the gas solid separation and the loop sealing between the reactors are of major concern for operation at high temperature and high pressure. This is one of the reasons that work was started on packed bed CLC, to investigate whether these problems could be circumvented (Noorman et al., 2007). The major advantage of packed bed CLC is that the gas/solid separation is intrinsically avoided, so that no fines are sent to the downstream gas turbine. It is also easier to pressurize packed beds than fluidized beds.

In a packed bed CLC, three main process steps can be identified in the cycle, although two of these steps essentially occur consecutively without change of input parameters. These three steps are (i) combined oxidation and heat generation, (ii) heat removal and (iii) reduction respectively. This is a crucial difference between packed bed and fluidized bed operation, in the latter case system steps (i) and (ii) occur simultaneously. These three steps will first be described explicitly in more detail below.

In the first step, the oxygen carrier is oxidized by feeding air to the packed bed. During this exothermic reaction, the oxygen carrier increases its oxidation state and heat is liberated by the reaction. When the oxidation front has reached the outlet of the reactor, the majority of the heat that has been generated by this oxidation is still present in the bed, accounted for by the hot solid and gas phases present in the reactor. In the second step, air continues to be fed into the reactor, and while no reaction occurs, the exhaust of the reactor is air that is heated to the temperature achieved in the reactor during the oxidation. The temperature is dictated by the oxygen carrier material choice and initial reactor conditions, but produces an essentially constant outlet temperature for the majority of this step (Noorman et al., 2007). This hot pressurized exhaust is converted into electricity downstream by a highly efficient gas turbine. In a third step, the feed stream in switched to syngas and the oxidation state of the oxygen carrier is reduced while syngas is converted to $\mathrm{CO}_{2}$ and steam. This hot exhaust can be used to generate electricity from the steam turbine in a combined cycle. The packed bed CLC cycle allows the use of a more efficient gas turbine for electricity generation. In low pressure fluidized bed CLC cycles, only a steam cycle is available for electricity generation.

Later in the paper, steps (i) and (ii) are described together as they are still very much related, even in packed bed operations; step (i) essentially occurs at the boundary of the oxidation front moving through the reactor, and step (ii) initially occurring upstream this oxidation front, and continuing after step (i) has reached completion.

In principle, the packed bed CLC process is a batch process, but by using several packed beds in parallel, a continuous hot pressurized air stream can be produced. A possible drawback of this process is that expensive high temperature valves may be required. The concept has been proven experimentally with methane as the fuel by Noorman et al. (2010). In the current study, the process developed by Noorman et al. is further extended to the use of syngas as the fuel.

As the packed bed CLC process is a cyclic process, the heat produced in the previous cycle influences the performance of the next cycle. This, in combination with the temperature dependency of the reactivity of the oxygen carrier, affects the switching scheme between oxidation and reduction. With regard to the reactivity of the oxygen carriers, Spallina et al. (2013) demonstrated that even oxygen carriers with low reactivity at lower temperatures, such as ilmenite, can be used in packed bed CLC by adapting the switching scheme between oxidation, heat removal and reduction. In this 
paper, the impact of the heat production and distribution in previous cycles on the current cycle is discussed in detail.

Finally, another challenge to using a packed bed for CLC is that, in normal oxidation/heat removal/reduction cycles, a large temperature rise should prevail in a single bed $\left(450-1200^{\circ} \mathrm{C}\right)$. While thermodynamically possible when considering calculations based on existing materials, it will be a challenge to find an oxygen carrier that realizes such a large temperature rise, while also showing high chemical and mechanical stability. An option to avoid such large temperature differences for the solid material is to carry out the process in two stages by using two packed beds in series instead of one single bed, where the first bed is responsible for the first temperature rise, demanding that the oxygen carrier should be reactive at low temperature (e.g. copper-based materials), while the second bed is responsible for the remaining temperature rise, and thus the oxygen carrier should be able to withstand higher temperatures. This two-stage approach will be described in detail in this paper.

The objectives of this paper are (i) to assess the feasibility of packed bed CLC with syngas as the fuel; (ii) to evaluate the influence of temperature profiles from a previous cycle on the efficiency of the next cycle and (iii) to demonstrate the feasibility of the twostage CLC concept with a comparison to the single stage concept. In the first section, the selection of an adequate oxygen carrier for CLC of syngas is discussed, focusing on the selectivity of oxygen carriers and the required amount of active material in the oxygen carrier to achieve the desired temperature rise. Subsequently, the process configuration is investigated with a numerical $1 \mathrm{D}$ reactor model that has been developed previously. Using this model, the effect of the operating conditions and reactor configuration on the reactor performance was studied when operating multiple cycles in a sequence. In the last section, a novel process is introduced and discussed in which the temperature rise could be achieved by two stages in series.

\section{Oxygen carriers for CLC with syngas}

In this section, the influence of the oxygen carrier selection on the reactor performance is studied for CLC with syngas as the fuel. A critical aspect in the oxygen carrier selection is its selectivity (i.e. the extent at which the syngas is converted into $\mathrm{H}_{2} \mathrm{O}$ and $\mathrm{CO}_{2}$ ), which is studied by thermodynamics. Another important aspect is the maximum temperature rise achieved during the process. Therefore, the temperature change in the reactor is examined for different oxygen carriers, including the temperature change during reduction with syngas.

\subsection{Thermodynamics of solid phases and reduction reactions}

In this work, four main oxygen carriers have been studied, based on nickel, copper, iron and manganese. The oxygen carrier materials are supported on materials like $\mathrm{Al}_{2} \mathrm{O}_{3}, \mathrm{MgAl}_{2} \mathrm{O}_{4}, \mathrm{SiO}_{2}, \mathrm{TiO}_{2}$ or $\mathrm{ZrO}_{2}$. The support material is added to increase the chemical and mechanical stability and to provide a porous structure. The porous structure is particularly desired for packed bed particles to combine good mass transport inside the particle with a limited pressure drop over the bed. Which support is selected depends mainly on the stability, porosity and costs.

\subsubsection{Selectivity of carriers}

The most studied oxygen carriers are nickel, copper, iron and manganese based. For an oxygen carrier for CLC application it is important that it completely converts syngas to $\mathrm{CO}_{2}$ and $\mathrm{H}_{2} \mathrm{O}$ in order to avoid fuel slip. In case of fuel slip, not all the reactants have reacted, leading to a decreased process efficiency and some downstream cleaning processes might be necessary as well.
Therefore, a selectivity very close to unity is required, which means that all $\mathrm{CO}$ and $\mathrm{H}_{2}$ is being converted into $\mathrm{CO}_{2}$ and $\mathrm{H}_{2} \mathrm{O}$.

Nickel is present as metallic $\mathrm{Ni}$ in reduced form and $\mathrm{NiO}$ in oxidized form. The selectivity to $\mathrm{CO}_{2}$ and $\mathrm{H}_{2} \mathrm{O}$ decreases with increasing temperature and, at $1000^{\circ} \mathrm{C}$, it is about $99 \%$ (Jerndal et al., 2006). The reduction will probably be carried out at a lower temperature and, in that case, this might not pose a serious problem. For copper, the selectivity is unity at all conditions. It may consist of three phases: $\mathrm{CuO}, \mathrm{Cu}_{2} \mathrm{O}$ and $\mathrm{Cu}$. However, because of the melting point of $\mathrm{Cu}$ at $1085^{\circ} \mathrm{C}$, the maximum temperature of this carrier is limited (and thus so is its applicability to single stage CLC).

Depending on the operating conditions, manganese and iron can be present in several phases. Manganese can be present as $\mathrm{Mn}_{2} \mathrm{O}_{3}$, $\mathrm{Mn}_{3} \mathrm{O}_{4}, \mathrm{MnO}$ and $\mathrm{Mn}$. $\mathrm{Mn}_{2} \mathrm{O}_{3}$ decomposes around $950^{\circ} \mathrm{C}$ and the reaction to $\mathrm{Mn}$ hardly prevails with syngas. So, for this study, only the phases $\mathrm{Mn}_{3} \mathrm{O}_{4}$ and $\mathrm{MnO}$ are considered. An overview of the reaction selectivities is shown in Table 1 . For $\mathrm{Mn}_{3} \mathrm{O}_{4}$ and $\mathrm{MnO}$, selectivity is not an issue. The selectivity could pose a problem for iron based oxygen carriers, which can be present as $\mathrm{Fe}_{2} \mathrm{O}_{3}$, $\mathrm{Fe}_{3} \mathrm{O}_{4}$, $\mathrm{FeO}$ and $\mathrm{Fe}$. $\mathrm{Fe}_{2} \mathrm{O}_{3}$ should not be further reduced than $\mathrm{Fe}_{3} \mathrm{O}_{4}$, because otherwise the selectivity drops to undesired values (Jerndal et al., 2006). This can be achieved by recycling $\mathrm{CO}_{2} / \mathrm{H}_{2} \mathrm{O}$ or adding steam to the syngas stream, so that the oxygen concentration is kept at a certain level.

\subsubsection{Carbon deposition}

If syngas is used as the fuel, carbon deposition on the oxygen carrier can occur, depending on the type of oxygen carrier and the operating conditions. Carbon formation is especially a concern when the degree of reduction is high, which is the case during reduction in a packed bed reactor since (at the inlet) syngas is in contact with a reduced oxygen carrier (Cho et al., 2005). Carbon deposition is caused by the Boudouard reaction, Eq. (1).

$2 \mathrm{CO} \rightleftarrows \mathrm{CO}_{2}+\mathrm{C}$

Due to carbon formation, the carbon capture efficiency is reduced. During oxidation, the carbon will be burnt to form $\mathrm{CO}_{2}$. This situation should be avoided as much as possible, because in the end this $\mathrm{CO}_{2}$ is emitted to the atmosphere instead of being captured. The Boudouard reaction occurs at low temperatures and high pressures. This equilibrium is independent of the oxygen carrier considered, but to what extent the Boudouard reaction occurs depends on the kinetics. It is known that nickel and iron are catalysts for the Boudouard reaction (Cho et al., 2005). When these carriers are used, the temperature should be kept high or $\mathrm{CO}_{2}$ and/or $\mathrm{H}_{2} \mathrm{O}$ has to be added to the syngas feed. For instance, when using $\mathrm{Cu} / \mathrm{Al}_{2} \mathrm{O}_{3}$ as the oxygen carrier, carbon deposition can be completely avoided at 20 bar and $450-1200^{\circ} \mathrm{C}$ by using a $\mathrm{H}_{2} \mathrm{O} / \mathrm{CO}$ ratio of 1.5 (Hamers et al., submitted for publication).

\subsubsection{Water gas shift reaction}

Another side reaction that could influence the process is the water gas shift reaction, Eq. (2).

$\mathrm{H}_{2}+\mathrm{CO}_{2} \rightleftarrows \mathrm{CO}+\mathrm{H}_{2} \mathrm{O}$

Below $823^{\circ} \mathrm{C}$, the equilibrium is on the $\mathrm{H}_{2}$ and $\mathrm{CO}_{2}$ side. Above this temperature, the equilibrium is on the $\mathrm{CO}$ and $\mathrm{H}_{2} \mathrm{O}$ side. The equilibrium is independent of the pressure. If pure syngas is fed to the process, the effect of the water gas shift reaction is negligible at the entrance of the reactor, because it can only occur when a mixture of reactants and products is present. If $\mathrm{H}_{2}$ reacts faster than $\mathrm{CO}, \mathrm{CO}$ can be converted with $\mathrm{H}_{2} \mathrm{O}$ into $\mathrm{CO}_{2}$ and $\mathrm{H}_{2}$, which is a faster reaction. In this case, the water gas shift reaction has an advantageous effect (Spallina et al., 2013). To prevent carbon 
Table 1

Properties of different metal/metal oxide pairs.

\begin{tabular}{|c|c|c|c|c|c|}
\hline Metal oxide & $\begin{array}{l}\text { Lowest melting } \\
\text { point }\left({ }^{\circ} \mathrm{C}\right)\end{array}$ & $\begin{array}{l}\text { Selectivity } \gamma_{\mathrm{CO}} \\
\text { at } 800^{\circ} \mathrm{C} \\
\text { (Jerndal et al., } \\
\text { 2006) }\end{array}$ & $\begin{array}{l}\text { Selectivity } \gamma_{\mathrm{H}_{2}} \text { at } \\
800{ }^{\circ} \mathrm{C} \text { (Jerndal } \\
\text { et al., 2006) }\end{array}$ & $\begin{array}{l}\text { Active weight } \\
\text { material required } \\
\text { for } 750^{\circ} \mathrm{CT} \text { rise }{ }^{\mathrm{a}} \\
\text { (Section } 2.2 \text { ) }\end{array}$ & $\begin{array}{l}\text { Costs (Lyngfelt, } \\
\text { 2011a) [€/ton] }\end{array}$ \\
\hline $\mathrm{NiO} / \mathrm{Ni}$ & 1455 & 0.995 & 0.995 & $19 \%$ & $>20,000$ \\
\hline $\mathrm{CuO} / \mathrm{Cu}$ & 1085 & 1.000 & 1.000 & $21 \%$ & $>3000$ \\
\hline $\mathrm{Fe}_{2} \mathrm{O}_{3} / \mathrm{Fe}_{3} \mathrm{O}_{4}$ & 1565 & 1.000 & 1.000 & b & $>1000$ \\
\hline $\mathrm{Fe}_{3} \mathrm{O}_{4} / \mathrm{FeO}$ & 1370 & 0.541 & 0.526 & c & $>1000$ \\
\hline $\mathrm{Mn}_{3} \mathrm{O}_{4} / \mathrm{MnO}$ & 1562 & 1.000 & 1.000 & $51 \%$ & $>1000$ \\
\hline
\end{tabular}

a In this calculation $\mathrm{Al}_{2} \mathrm{O}_{3}$ was considered as support material.

b It is not possible to reach a $750^{\circ} \mathrm{C}$ temperature rise with only the $\mathrm{Fe}_{2} \mathrm{O}_{3} / \mathrm{Fe}_{3} \mathrm{O}_{4}$ oxygen carrier pair.

c Because of the low selectivity, the active weight content for a $750{ }^{\circ} \mathrm{C}$ temperature rise is not relevant.

deposition, $\mathrm{CO}_{2}$ and/or $\mathrm{H}_{2} \mathrm{O}$ can be added to the fuel and, in that case, the water gas shift reaction can have an important role.

\subsection{Temperature change with syngas as fuel}

The temperature increase in the packed bed should be large enough to generate power at a high efficiency. The temperature increase in a packed bed reactor can be calculated with Eq. (3) (Noorman et al., 2007). In this equation, the initial bed temperature is assumed to be equal to the gas inlet temperature and the thermodynamic properties are assumed to be independent of temperature.

$\Delta T=\frac{-\Delta H_{R, i}}{\left(C_{p, s} M_{\mathrm{act}} / \omega_{\mathrm{act}}^{0} \varsigma\right)-\left(C_{p, g} M_{g, i} / \omega_{g, i}^{\mathrm{in}}\right)}$

From Eq. (3) it is shown that the temperature increase is not influenced by the flow rate and the kinetics. For this case, a change in flow rate or a slight change in the activity (kinetics) will not affect the temperature of the gas stream fed to the gas turbine. This approach is only valid for separated reaction and heat fronts If the difference in front velocities is small (due to low solid reactivity or high dilution of gas reactants), no temperature plateau is produced, but rather a moving temperature peak. The height of this peak is influenced by the kinetics.

In Fig. 1, the temperature rise during oxidation is shown as a function of the active metal content in the oxygen carrier material. It is assumed that the initial and the inlet temperature is $450^{\circ} \mathrm{C}$, but these temperatures have little influence on the temperature rise (because the temperature dependency of the reaction enthalpy

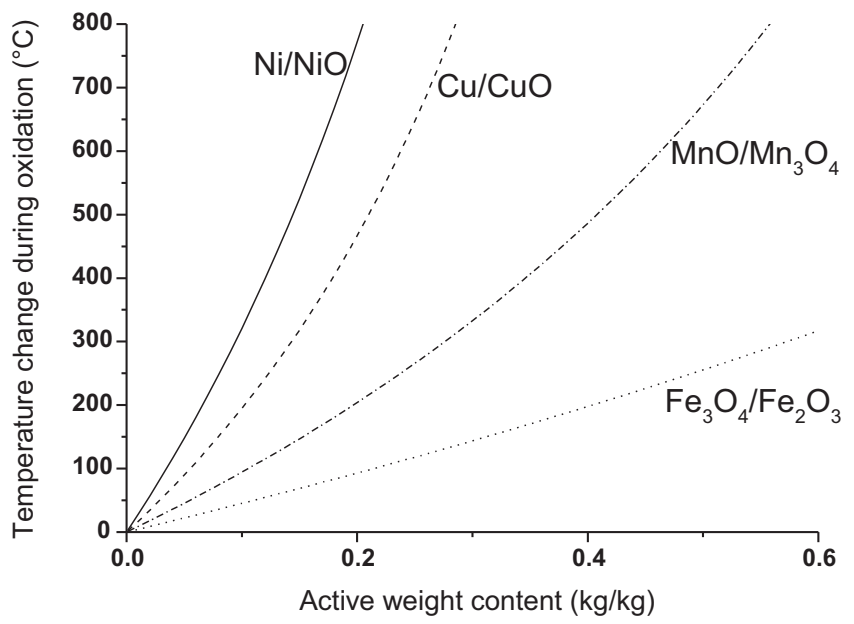

Fig. 1. The temperature rise for the most general oxygen carriers as a function of the active weight content in the oxygen carrier (air inlet temperature of $450{ }^{\circ} \mathrm{C}$ ). and the solid heat capacity is very moderate). Although manganese and iron could be present in several phases, in this calculation, only the reactions between $\mathrm{Mn}_{3} \mathrm{O}_{4} / \mathrm{MnO}$ and the $\mathrm{Fe}_{2} \mathrm{O}_{3} / \mathrm{Fe}_{3} \mathrm{O}_{4}$ are considered. The thermodynamic properties were obtained from (Barin, 1993; Daubert and Danner, 1985). The desired temperature increase during oxidation should be around $750{ }^{\circ} \mathrm{C}$, because air is fed at $450^{\circ} \mathrm{C}$ (typical temperature of the air in IGCC plants after compression to 20 bar) and should be heated up to $1200^{\circ} \mathrm{C}$ to be fed to the downstream gas turbine. According to the results presented in Fig. 1, the oxygen carrier content can be tuned, such that the desired temperature increase is achieved. For instance, using $\mathrm{Ni}$ as the oxygen carrier would require an active content of less than $20 \mathrm{wt} \%$, which would also result in higher mechanical stability (Hossain and de Lasa, 2007; Sedor et al., 2008; Hossain et al., 2009). The disadvantages of nickel is that the costs are higher compared to the other oxygen carriers and that safety measures have to be taken due to its toxicity (Adanez et al., 2012). Copper could in principle also be used because of its high oxygen capacity, resulting in a steep temperature rise as a function of active content in the oxygen carrier material; however, the low temperature melting point makes this material unsuitable for high temperatures. Using Mn as the oxygen carrier would require a greater amount of active material in the particles to reach the desired temperature rise, with possible consequent detrimental effect on the mechanical stability during the different oxidation/reduction cycles. Finally, using Fe as the oxygen carrier and limiting the reduction to $\mathrm{Fe}_{3} \mathrm{O}_{4}$ would not be sufficient to reach the desired temperature rise in a single bed; and further reducing iron is not an option as the selectivity drops to undesired values (i.e. at $800^{\circ} \mathrm{C}$ the selectivity to $\mathrm{CO}_{2}$ is 0.541 and to $\mathrm{H}_{2}$ is 0.526 (Jerndal et al., 2006)). The results of this calculation also suggest that a combination of oxygen carriers can be used to achieve the total temperature rise required. For instance, using a first bed with $\mathrm{Cu}$ as the oxygen carrier to reach a first temperature rise of about $400-500^{\circ} \mathrm{C}$ (well below the melting point of $\mathrm{Cu}$ ) will then require a second bed with $\mathrm{Mn}$ or Fe as the oxygen carrier with lower active material content, and thus also the stability of the second oxygen carrier would probably be enhanced. This option will be discussed in this paper as a two-stage configuration in Section 5.

In Figs. 2 and 3, the temperature change caused by the reduction is also reported. In case syngas is used, the temperature change is an average (depending on the $\mathrm{CO} / \mathrm{H}_{2}$-ratio). Unlike the reduction with methane, which is often endothermic, the reduction with syngas is an exothermic reaction (except for the reduction of $\mathrm{Fe}_{2} \mathrm{O}_{3}$ with $\mathrm{H}_{2}$ ). The advantage of an exothermic reaction is that the temperature of the reactor will not drop during the reduction, which would have a negative effect on the reaction rates and, therefore, the process efficiency. However, attention has to be paid on how the heat gained during reduction can be used in the most efficient way, which is discussed in Section 4. 


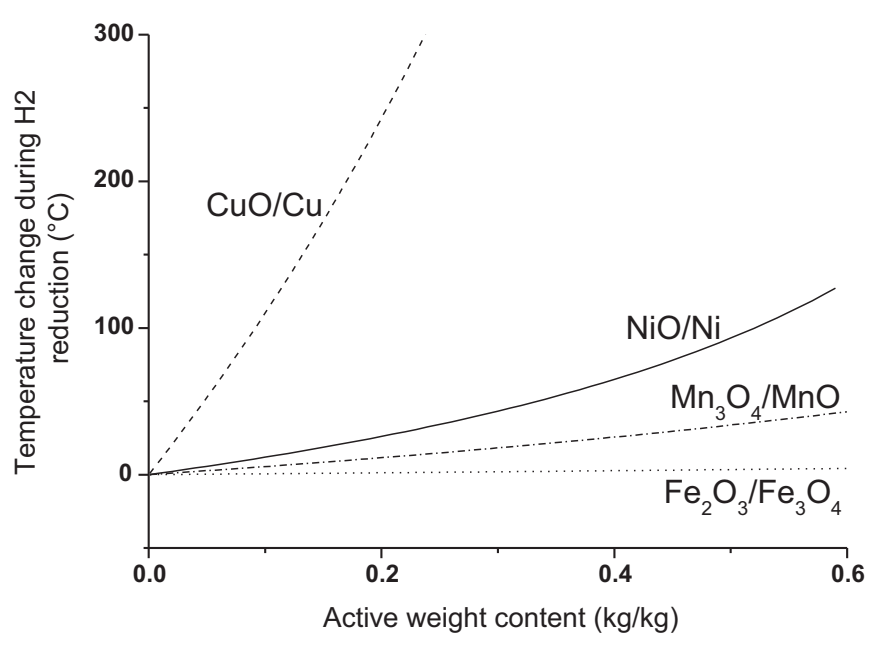

Fig. 2. The temperature change due to the reduction with pure $\mathrm{H}_{2}$ as a function of the active weight content in the oxygen carrier (inlet temperature of $450^{\circ} \mathrm{C}$ ).

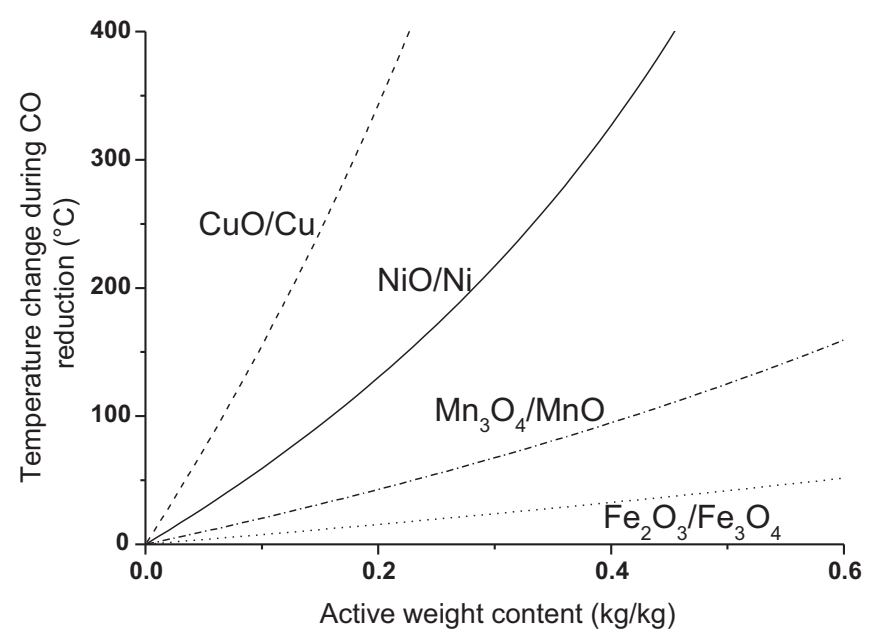

Fig. 3. The temperature change due to the reduction with pure $\mathrm{CO}$ as a function of the active weight content in the oxygen carrier (inlet temperature of $450^{\circ} \mathrm{C}$ ).

\section{Packed bed reactor model}

For describing the axial temperature and concentration profiles in a packed bed CLC reactor, a numerical 1D packed bed reactor model has been developed previously (Noorman et al., 2007). In Table 2 the reactor model equations are listed. In this model it is assumed that the reactor is an adiabatic packed bed reactor, which means that no heat losses through the wall are considered. No radial temperature and concentration gradients are considered as well and the model is pseudo-homogeneous (no temperature difference between particles and gas). The model has already

Table 2

The mass and energy balances used in the model.

$$
\begin{aligned}
& \text { Component mass balances for the gas phase } \\
& \varepsilon_{g} \rho_{g} \frac{\partial \omega_{i, g}}{\partial t}=-\rho_{g} v_{g} \frac{\partial \omega_{i, g}}{\partial x}+\frac{\partial}{\partial x} \rho_{g} D_{\mathrm{ax}} \frac{\partial \omega_{i, g}}{\partial x}+\varepsilon_{g} r_{i} M_{i} \\
& \text { Component mass balance for the solid phase } \\
& \varepsilon_{s} \rho_{s} \omega_{\mathrm{act}}^{0} \frac{\partial \omega_{s, j}}{\partial t}=\varepsilon_{g} r_{j} M_{j} \\
& \text { Energy balance (gas and solid phase): } \\
& \left(\varepsilon_{g} \rho_{g} C_{p, g}+\varepsilon_{s} \rho_{s} C_{p, s}\right) \frac{\partial T}{\partial t}=-\rho_{s} v_{g} C_{p, g} \frac{\partial T}{\partial x}+\frac{\partial}{\partial x}\left(\lambda_{\text {eff }} \frac{\partial T}{\partial x}\right)+\varepsilon_{g} r_{i} \Delta H_{R, i} \\
& \text { Reaction rate } \\
& r_{i}=k_{\text {eff }} C_{g, i}^{n} C_{s, j}^{0}
\end{aligned}
$$

Table 3

Constitutive equations for the description of heat and mass dispersion.

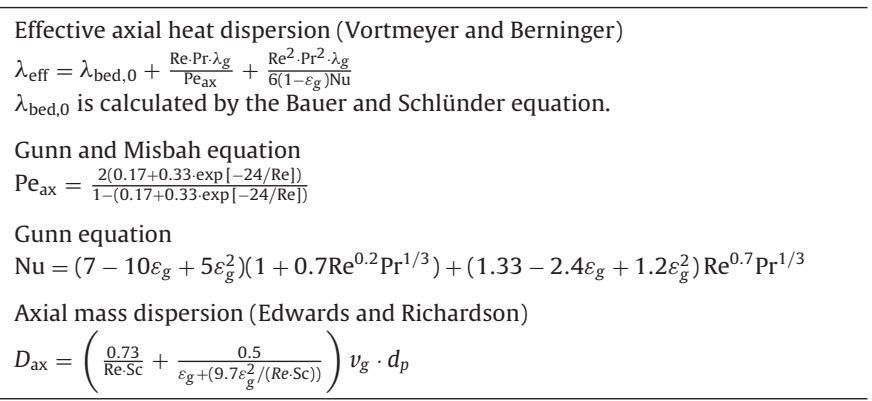

been experimentally validated for CLC using methane as the fuel (Noorman et al., 2010).

In this work, it is assumed that the syngas is fully converted into $\mathrm{CO}_{2}$ and $\mathrm{H}_{2} \mathrm{O}$, which means that the carbon deposition reaction is not considered and selectivities are assumed to be equal to unity. If carbon deposition would be included, some $\mathrm{CO}$ is converted into $C$ during reduction and burnt off of the carrier during oxidation, resulting in a lower carbon efficiency. Moreover, it is considered that the water gas shift reaction does not take place. As was discussed in Section 2.1.3, the effect of this reaction in terms of heat is small and would only improve the reaction rate, so this assumption can be made safely for this study.

In the mass and energy balances, there are terms for the axial mass dispersion and the effective heat conductivity, respectively. The closure equations used for these terms are summarized in Table 3. For more details on the model and the numerical solution strategy, the interested reader is referred to Smit et al. (2005) and Noorman et al. (2007).

\subsection{Base case definition}

For this study, a base case has been defined with $\mathrm{CuO} / \mathrm{Al}_{2} \mathrm{O}_{3}$ as the oxygen carrier. $\mathrm{CuO} / \mathrm{Al}_{2} \mathrm{O}_{3}$ has been selected because of its fast reaction rates at low temperature, high oxygen capacity and high selectivity. Moreover, it is one of the few commercially available oxygen carriers for packed beds and can thus be used in a future work for model validation. Although the melting point of $\mathrm{Cu}$ is lower than the $1200^{\circ} \mathrm{C}$ required for high efficiency, a packed bed with $\mathrm{CuO} / \mathrm{Al}_{2} \mathrm{O}_{3}$ can be used as the first stage in a two stage system, as discussed in the following sections. Thus Cu-based oxygen carriers are still interesting when a high temperature has to be reached.

The specific oxygen carrier considered consists of $12.5 \mathrm{wt} \%$ $\mathrm{CuO} / \mathrm{Al}_{2} \mathrm{O}_{3}$ with a particle porosity of $60 \%$ (as commercially available). Considering a gas porosity in the reactor of $40 \%$, a solid bulk density of $999 \mathrm{~kg} / \mathrm{m}^{3}$ is reached in the oxidized state.

The highest energy efficiency in the gas turbine can be reached at a pressure of around 20 bar. The air for the oxidation is supplied by the compressor of the turbine and is assumed to be delivered at a temperature of $450^{\circ} \mathrm{C}$. Flow rates and reactor lengths are selected such that the maximum pressure drop is $1 \mathrm{bar}(5 \%)$ and the duration of a cycle is around $10 \mathrm{~min}$. Therefore, a particle size of $3 \mathrm{~mm}$ is selected combined with a flow rate of $5 \mathrm{~kg} /\left(\mathrm{m}^{2} \mathrm{~s}\right)$ during oxidation. Within $600 \mathrm{~s}$, the bed is almost completely reduced at a flow rate of $0.15 \mathrm{~kg} /\left(\mathrm{m}^{2} \mathrm{~s}\right)$, which is a factor 30 smaller than the flow rate during oxidation.

For the fuel, syngas is selected with a $\mathrm{H}_{2} / \mathrm{CO}$ ratio of 1 . In this study, a simplified approach (with only a constant and first order reaction) was used to describe the kinetics based on reaction rates published in literature (García-Labiano et al., 2004). The constant has been estimated conservatively to account for possible diffusion limitations. The operating conditions for the base case are listed in 
Table 4

Defined base case for the reactor model simulations.

\begin{tabular}{llll}
\hline Oxygen carrier & & $12.5 \mathrm{wt} \% \mathrm{CuO}$ on $\mathrm{Al}_{2} \mathrm{O}_{3}$ \\
Particle diameter $[\mathrm{mm}]$ & 3 & \\
Solids bulk density in oxidized state, $\varepsilon_{s} \rho_{\mathrm{s}}\left[\mathrm{kg} / \mathrm{m}^{3}\right]$ & 999 & \\
Gas porosity $\left[\mathrm{m}_{\text {gas }}^{3} / \mathrm{m}_{\text {reactor }}^{3}\right]$ & & 0.4 & \\
Reactor length [m] & 4.0 & \\
& & & \\
& Oxidation/heat removal & Reduction & Purge \\
\hline Gas inlet flowrate $\left[\mathrm{kg} /\left(\mathrm{m}^{2} \mathrm{~s}\right)\right]$ & 5 & 0.15 & 2 \\
Gas inlet [mol fraction] & $\mathrm{O}_{2}: 0.21$ & $\mathrm{H}_{2}: 0.5$ & $\mathrm{~N}_{2}: 1$ \\
& $\mathrm{~N}_{2}: 0.79$ & $\mathrm{CO}: 0.5$ & \\
Gas inlet temperature [ $\left.{ }^{\circ} \mathrm{C}\right]$ & 450 & 450 & 450 \\
Gas inlet pressure $[\mathrm{bar}]$ & 20 & 20 & 20 \\
Reaction rate, $r_{i}$ & $50 \mathrm{c}_{2}$ & $25 \mathrm{c}_{\mathrm{H}_{2}}$ & - \\
[mol/(m $\left.\left.{ }^{3} \mathrm{~s}\right)\right]$ & & $25 \mathrm{c}_{\mathrm{CO}}$ & \\
Cycle time [s] & 730 & 600 & 10 \\
\hline
\end{tabular}

Table 4. The results shown in the next sections are based on these conditions.

\section{Simulation results}

First, the temperature and concentration profiles for a single oxidation or reduction step, assuming a uniform initial temperature throughout the reactor, are shown. These results are used to discuss the heat and reaction fronts occurring in the reactor as well as to evaluate the time period at which high temperature air is produced, and thus to define a process efficiency. Subsequently, results for the cyclic steady state after several alternating cycles are presented and discussed. These results are interesting because, in practice, there is always a remaining temperature profile from the previous cycle, which influences the performance of the next cycle. These temperature effects were not studied in detail or considered in previous literature works for CLC, where it was, for example, assumed that the temperature profiles were equalized via short periods of intermediate mild fluidization (Noorman et al., 2007). To what extent the remaining temperature profile in each cycle influences the performance is discussed in Section 4.2. Furthermore, different feeding strategies are evaluated with a particular focus on the difference between co-current and counter-current feeding of the oxidizing and reducing feed streams.

\subsection{Single cycle}

\subsubsection{Reduction step}

During reduction, the bed initially contains only $\mathrm{CuO} / \mathrm{Al}_{2} \mathrm{O}_{3}$. When syngas is fed, $\mathrm{CO}$ and $\mathrm{H}_{2}$ react with $\mathrm{CuO}$ to form $\mathrm{CO}_{2}$ and $\mathrm{H}_{2} \mathrm{O}$. Due to the reduction of the carrier, a reaction front develops through the reactor (Fig. 4). The steepness of this front depends on the reaction kinetics and axial mass and heat dispersion.

The same type of front is observed in the temperature profile. Initially, the reactor temperature is uniform at $450{ }^{\circ} \mathrm{C}$. When feeding syngas at $450^{\circ} \mathrm{C}$, the exothermic reduction reaction takes place and the temperature rises in the reactor. The temperature increases exactly where the reaction takes place, thus the temperature profile also shows the reaction front in the bed. As the feed temperature of the syngas is different from the temperature of the bed, a heat front moves through the bed as well, with a speed lower than the reaction front. These fronts are described by Eqs. (4) and (5) (Noorman et al., 2007). Since the heat front develops slower than the reaction front, a heat plateau arises in the bed, as shown in Fig. 4.

$w_{r}=\frac{\rho_{g} v_{g} \omega_{g}^{\mathrm{in}} M_{\mathrm{act}}}{\varepsilon_{s} \rho_{s} \omega_{\mathrm{act}}^{0} M_{g, i} \zeta}$
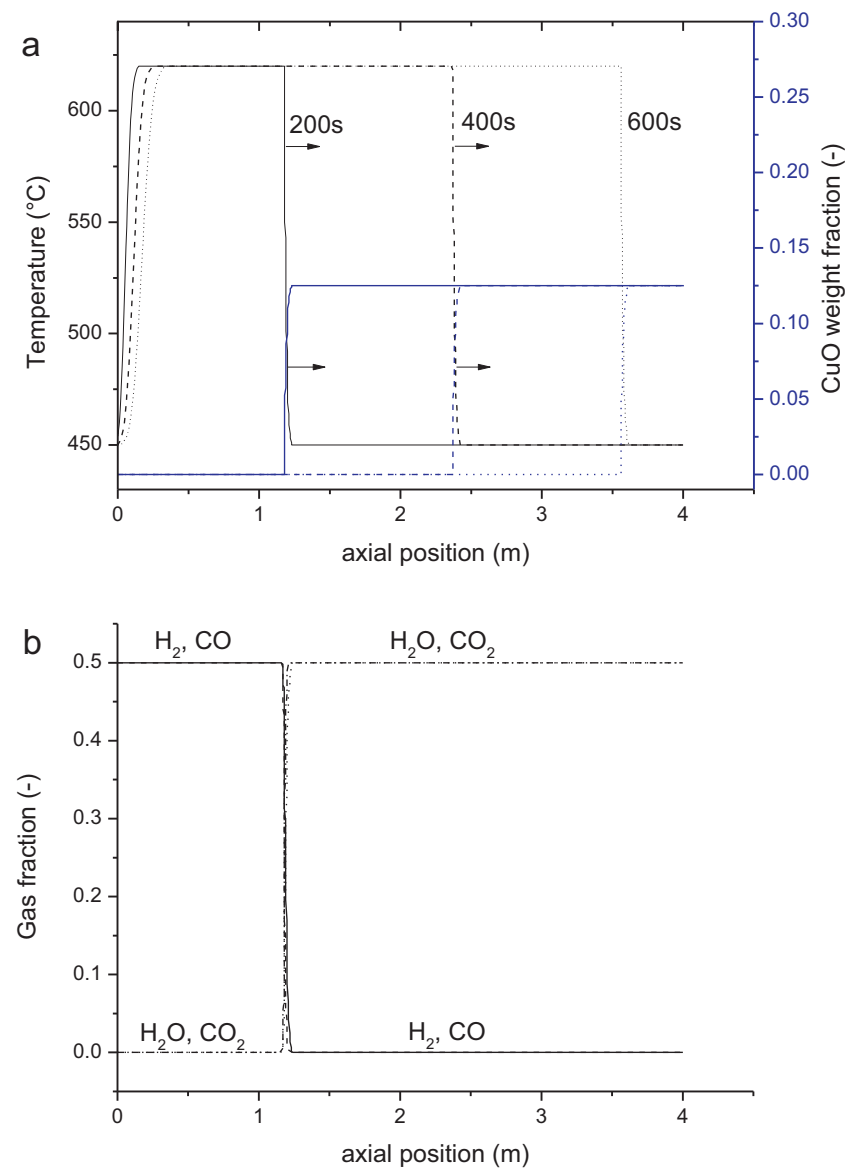

Fig. 4. Axial temperature and solid concentration profiles in the reactor during the reduction step.

$w_{h}=\frac{\rho_{g} v_{g} C_{p, g}}{\varepsilon_{s} \rho_{s} C_{p, s}}$

\subsubsection{Oxidation and heat removal step}

The oxidation step is started with a uniform bed temperature of $450{ }^{\circ} \mathrm{C}$ and $\mathrm{Cu} / \mathrm{Al}_{2} \mathrm{O}_{3}$ as the bed material. The reduced carrier reacts with $\mathrm{O}_{2}$ to form $\mathrm{CuO}$ (oxidized carrier). This reaction is more exothermic than the reduction reaction, resulting in a larger temperature change. The axial temperature profiles and the oxygen gas fraction profiles during the oxidation cycle are shown in Fig. 5. At a certain moment in time, the oxygen carrier has been oxidized completely. Then (at about $100 \mathrm{~s}$ for this simulation), the heat front reaches the end of the reactor and, from this moment in time, hot air is produced at the same temperature of the bed, which can be fed to a gas turbine to produce electricity. The temperature and oxygen concentration of the outlet stream of the reactor as a function of time is depicted in Fig. 6. Hot air is produced until the heat front reaches the end of the reactor. Unfortunately, the heat front is not a steep front due to heat dispersion. Thus some heat cannot be effectively used and would remain in the reactor (or be wasted).

In actual operation, the bed will experience alternating cycles and thus two main aspects will change compared with the single cycle just described. First, the reduction cycle will be stopped when the extent of fuel slip reaches the maximum value allowed. In this case, the bed is not fully reduced, as was assumed in the single reduction cycle. Second, during heat removal, not all of the heat is blown out of the bed because, at a certain moment, the outlet temperature drops below the limit that a gas turbine can 

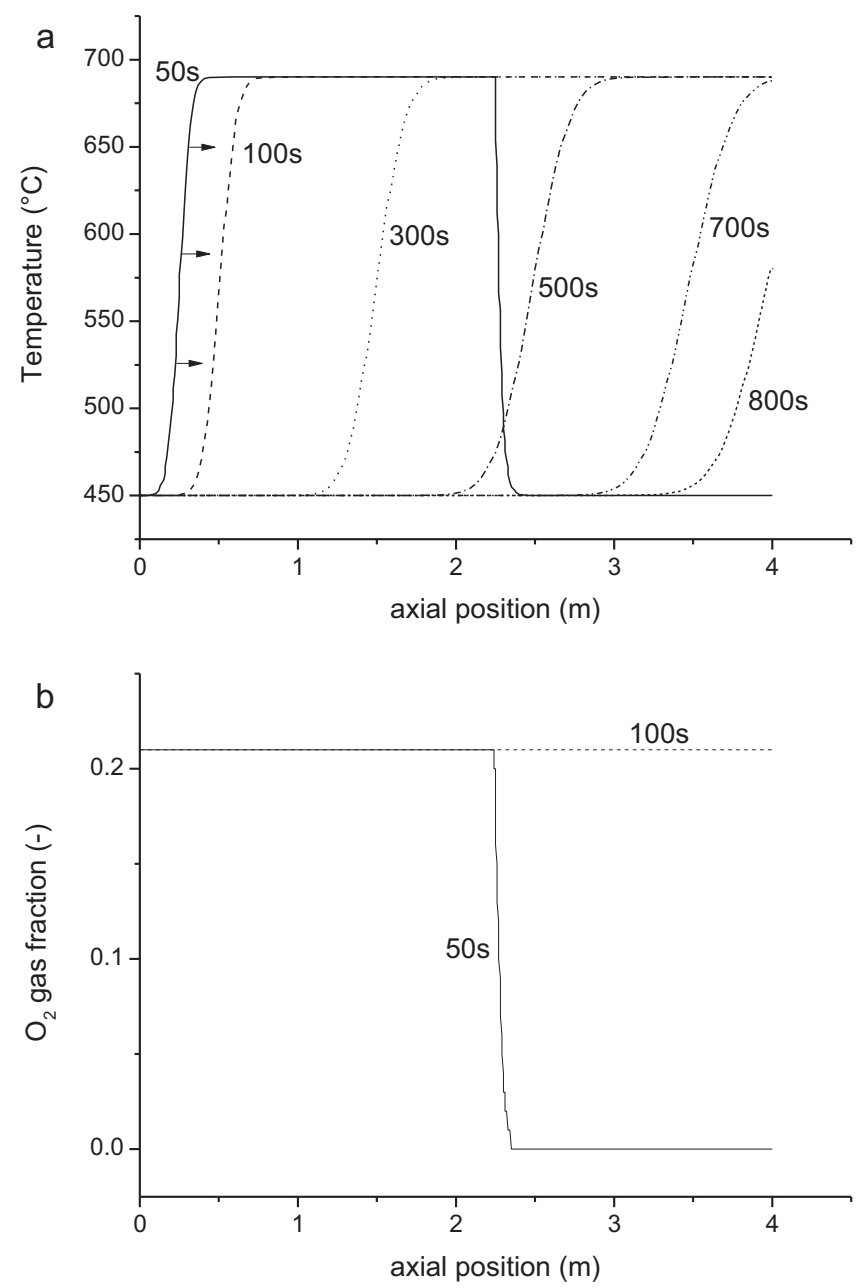

Fig. 5. Axial temperature and concentration profiles in the reactor during the oxidation and heat removal step.

handle in an efficient way. Thus, the initial temperature profile for the subsequent reduction is not a flat profile, as was again assumed in the single cycle case, but instead a temperature profile prevails with a higher temperature in the final part of the reactor. To what extent these effects influence the subsequent cycles is discussed in the next section.

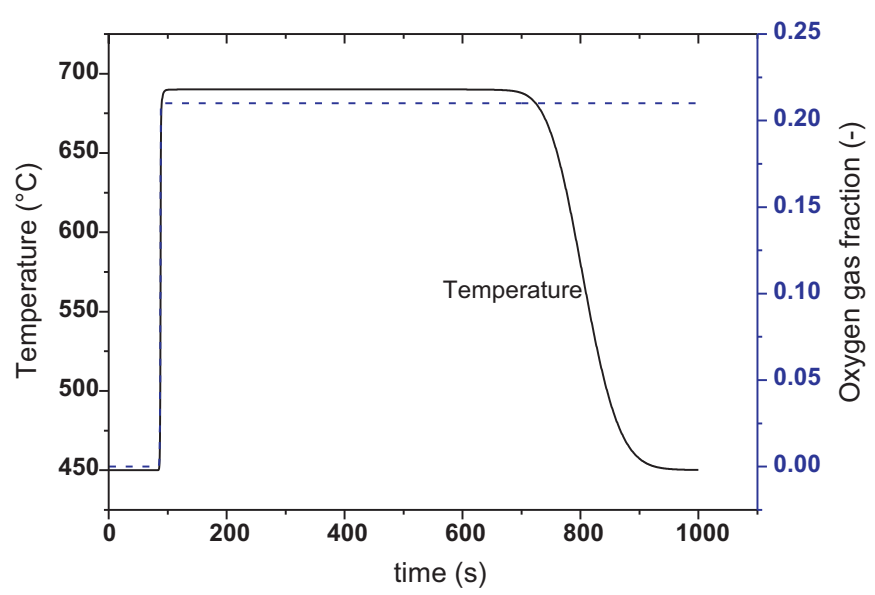

Fig. 6. Concentration and temperature profiles of the outlet stream of the reactor during oxidation and heat removal.
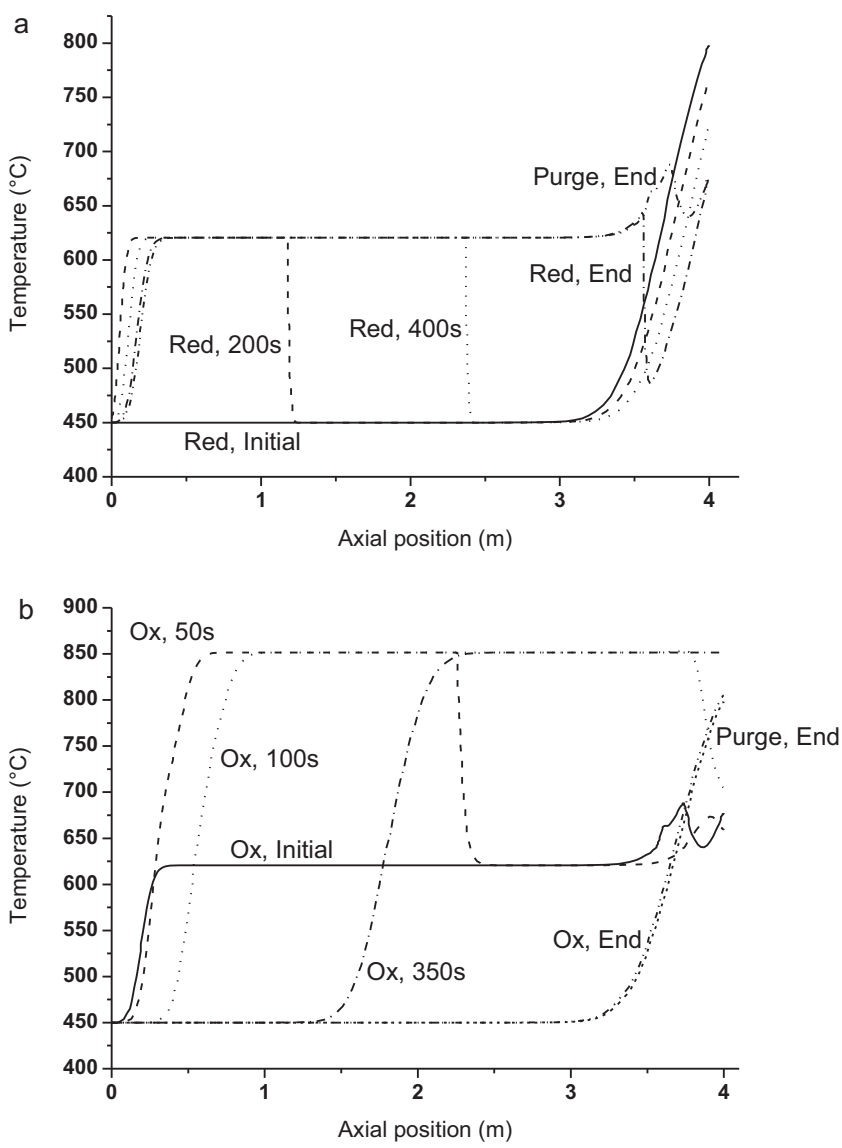

Fig. 7. Axial temperature profiles during (a) reduction and (b) oxidation (including heat removal) for the base case in the cyclic steady state.

\subsection{Multiple cycles}

Now, the cyclic steady state is considered after several oxidation and reduction cycles (with intermediate purge cycles). Typically, the cyclic steady state is almost attained after only a few full cycles, as shown later. The reduction cycle is started when the outlet temperature has dropped to a level at which the gas turbine cannot work efficiently. At that point, the bed has a higher temperature at the end than in the rest of the bed, which has the same temperature as the inlet air during the oxidation cycle, in this case $450^{\circ} \mathrm{C}$ (see Fig. 7a). When the reduction cycle starts, the bed temperature increases because the reduction with syngas is also exothermic. During this time, the outlet temperature declines because the heat at the end of the bed is partially blown out of the bed. When fuel slip occurs, the reduction cycle has to be stopped. To prevent fuel slip, the cycle is stopped before all of the solids have undergone a reduction, especially at the end of the bed. The heat produced during the reduction cycle is stored in the bed. It should be noted that in this simulation the reduction and oxidation cycle times were specified to simplify the discussion and analysis. In actual operation, the moment to stop the oxidation and reduction cycles is controlled by the outlet temperature (or outlet composition).

After the reduction cycle, the reactor is purged with $\mathrm{N}_{2}$ for $10 \mathrm{~s}$ to prevent that syngas and oxygen are in contact. In this step, the remaining syngas in the bed also reacts with the carrier, causing a slight temperature change at the end of the bed, shown in Fig. 7a. The purge is carried out at a higher flow rate than during the reduction cycle and, due to the flow increase, some fluctuations are observed in the temperature profile at the end of the bed. 


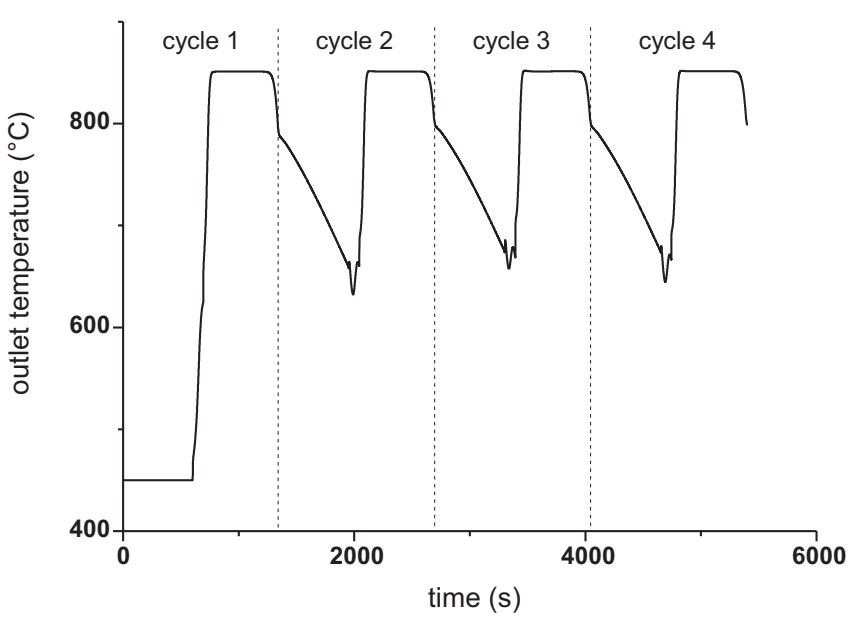

Fig. 8. Evolution of the outlet temperature in time after repeated reduction and oxidation (and heat removal) cycles for the base case.

It should be noted that in real operation, the purge time would also be optimized, but this is not in the scope of the present paper.

After the short purge, the oxidation cycle is started. When the reaction front develops through the bed, the bed temperature rises as well. At the outlet, a temperature increase is observed because of the heat remaining from the reduction reaction. Then the outlet temperature decreases, until the moment that the reaction front arrives at the end of the bed (i.e. the moment that almost the entire bed has been oxidized again, in Fig. $7 \mathrm{~b}$ this is at $t_{\text {oxidation }} \approx 100 \mathrm{~s}$ ). From that moment, hot air is blown out of the bed at a constant temperature (this is the heat removal step). In the first instance, the air temperature is slightly higher, which is caused by the remaining heat from the previous oxidation cycle. The hot air generation process (heat removal) continues until the temperature drops below the limit set by the gas turbine. After a short purge, the bed is reduced again.

The outlet temperature profiles of the first four reduction and oxidation cycles are depicted in Fig. 8. After the third cycle, repeated behavior can be observed, which is illustrated in more detail in Fig. 9. It is shown that during the reduction, the outlet temperature drops slightly because the remaining heat from the previous cycle is partially blown out of the bed; this behavior can also be observed

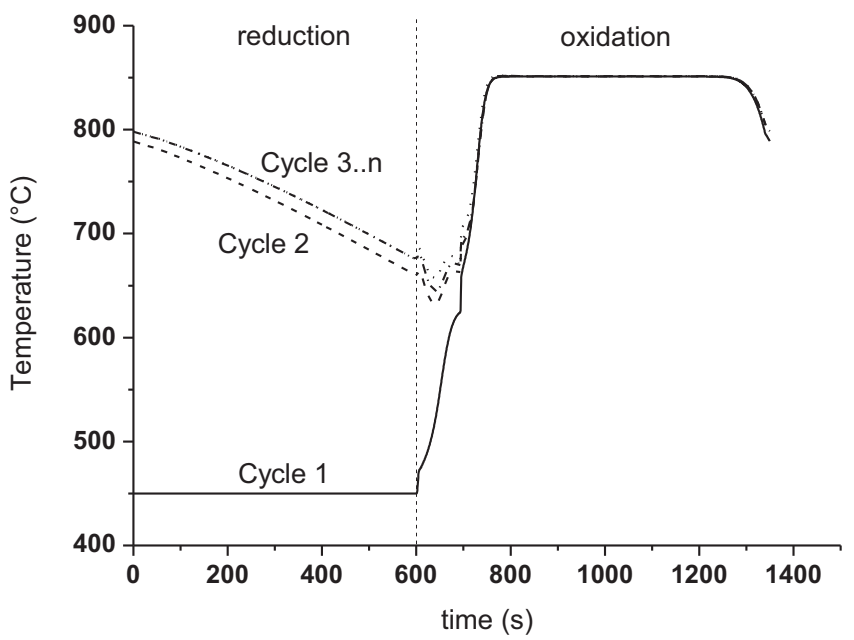

Fig. 9. Outlet temperature as a function of the time after starting a full cycle for repeated reduction and oxidation (including heat removal) cycles for the base case. Between $t=700 \mathrm{~s}$ and $t=1200 \mathrm{~s}$, air with a constant temperature is produced, that can be used for power generation in a gas turbine.

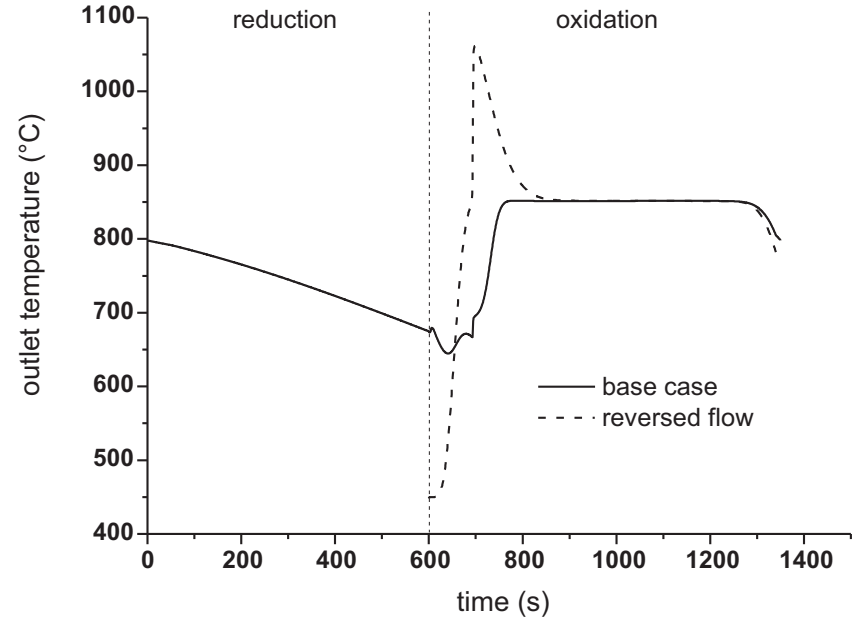

Fig. 10. Comparison between the reversed flow option and the base case.

in the axial profiles in Fig. 7a. After starting the oxidation cycle, the outlet temperature has some small fluctuations until the moment that the reaction front reaches the end of the bed (end of oxidation phase). After that moment, the heat removal phase starts, when hot air is produced. The heat removal phase is the largest phase of the oxidation cycle.

In Fig. 9, it is shown that hot air is produced with a constant temperature, which is required for the downstream power generation unit. It should also be noted that the flow during oxidation is much higher than during reduction. For that reason, $85 \%$ of the generated energy during the combustion reactions is converted into air at a temperature above $800^{\circ} \mathrm{C}$, which gives an indication of the energy efficiency of the process.

Simulations with other oxygen carriers lead to very similar profiles with different temperatures due to a difference in reaction enthalpy and active weight content (resulting in another $w_{h} / w_{r}$ ratio). As shown in Section 2, the reaction enthalpy of the reduction of nickel, iron or manganese with $\mathrm{H}_{2}$ and $\mathrm{CO}$ is less exothermic. For that reason, the only difference is the profile at the beginning of the oxidation cycle (before the bed is oxidized and hot air is produced)

As is shown in the gas outlet temperature profile (Fig. 9), not all the heat that is released due to the exothermic reactions is used for hot air production. In the next section, the effect of the cycle transition method is discussed to evaluate if the process efficiency can be increased by effectively using this remaining heat.

\subsection{Cycle transition method}

The remaining energy from the oxidation cycle could be used efficiently by reversing the flow direction during reduction; in that case the syngas is fed counter-currently (thus from the hottest part of the reactor). In this situation, heat at the hottest part of the reactor $(z=L)$ is blown back into the bed instead of blown out of the reactor. For that reason, this option is more energy efficient. A comparison in terms of temperature profiles with the base case is shown in Fig. 10.

During the reduction, $\mathrm{CO}_{2}$ and $\mathrm{H}_{2} \mathrm{O}$ are produced at the temperature at $z=0$ (equal to the air inlet temperature, $450^{\circ} \mathrm{C}$ ). After switching to the oxidation and heat removal step (and changing the flow direction), all the remaining heat from the previous cycle that has accumulated at $z=L$ is blown out of the bed. From the peak at the outlet temperature profile, it can be concluded that the remaining heat was not distributed well over the bed. During the reduction reaction, two heat transport processes take place. First, a heat front moves through the bed and, second, heat dispersion 


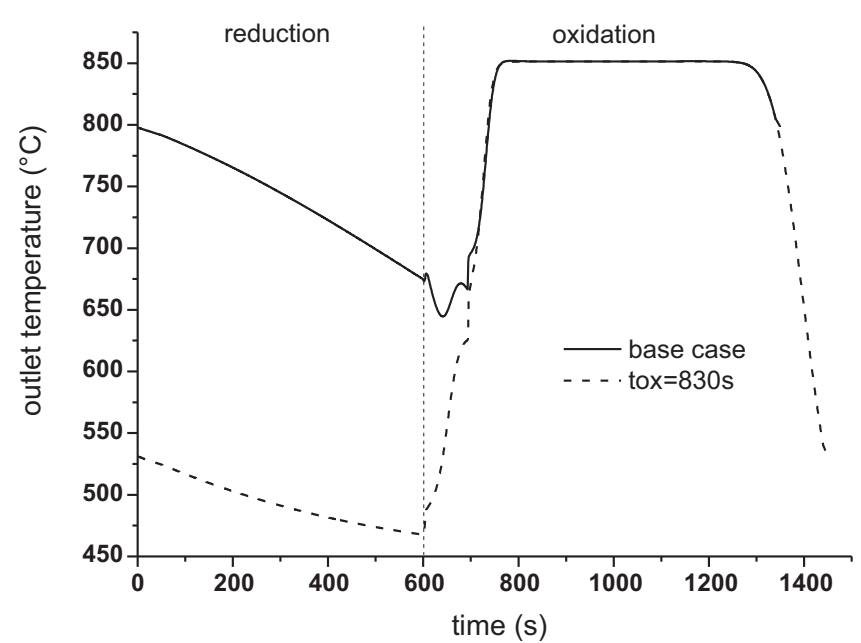

Fig. 11. The effect of increasing the oxidation time by $100 \mathrm{~s}\left(t_{\mathrm{ox}}=730 \mathrm{~s}\right.$ and $\left.830 \mathrm{~s}\right)$.

occurs. However, those processes occur quite slowly resulting in a maldistributed temperature profile.

In the case of countercurrent flows, a larger temperature peak is observed in the outlet temperature profile. Although more heat can be used, this larger fluctuation in temperature is probably not easily accommodated in the downstream power generation unit. This will also affect the properties of the oxygen carrier. For these reasons the countercurrent operation is not preferred. Additionally, the countercurrent operation also implies the use of high temperature valves at both ends of the reactor, which makes this operation also less attractive from an economical point of view. An alternative solution to equalize the temperature profiles in the bed, thus utilizing the remaining heat in an effective way, is to fluidize the oxygen carrier for a short period by steam as proposed by Noorman et al. (2007). However, by fluidizing the oxygen carrier, the mechanical stability becomes more of an issue and fines could be created, which could give rise to increased pressure drop during the oxidation cycle.

\subsection{Process design parameters}

In addition to the flow direction switching scheme, several other parameters can be tuned to optimize the power generation efficiency. In this section, two main options are discussed that might lead to a higher energy efficiency. Whether or not a higher electrical efficiency is reached, depends on the different power generation processes that are applied to generate electricity and this will be studied in future work.

(1) The length of the oxidation/heat removal time can be extended. The effect is depicted in Fig. 11, where the oxidation cycle is extended by $100 \mathrm{~s}$. In this case, more heat is blown out of the bed during the heat removal step, resulting in a lower outlet temperature of $\mathrm{CO}_{2}$ and $\mathrm{H}_{2} \mathrm{O}$ during reduction. The period of time at which the hot air is produced at $>850^{\circ} \mathrm{C}$ does not change. The difference between the two cases is the temperature of the $\mathrm{CO}_{2} / \mathrm{H}_{2} \mathrm{O}$ stream and the air at lower temperature. A system evaluation has to be carried out to show at what point the heat removal step has to be stopped to reach the highest overall electrical efficiency.

(2) From the desulphurization plant the syngas might be obtained at a lower temperature. Therefore the influence of the syngas temperature has been studied. Feeding syngas at a lower temperature (for example $100^{\circ} \mathrm{C}$ ) will not have much influence on the conversion and temperature profiles, because the syngas

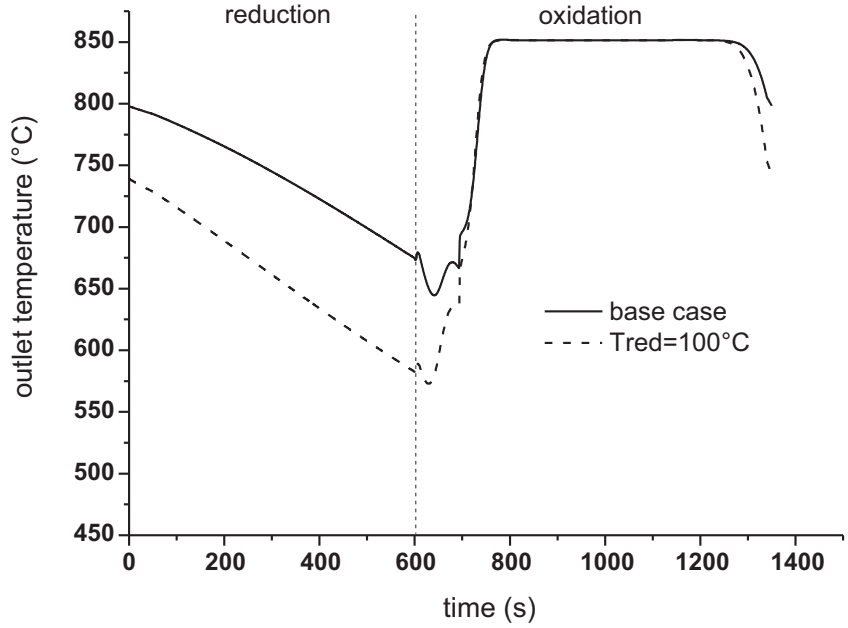

Fig. 12. The effect of the syngas temperature $\left(T_{\text {red }}=450^{\circ} \mathrm{C}\right.$ and $\left.100^{\circ} \mathrm{C}\right)$.

flow rate is much smaller than the air flow rate and enough heat is already available in the bed to heat up the feed. On the other hand, feeding syngas at a low temperature avoids the use of heat exchangers (i.e. to heat up syngas to $450^{\circ} \mathrm{C}$ ) and thus increases the efficiency of the entire power plant. As shown in Fig. 12, hot air is produced at the same temperature as in the base case. However, the time in which the hot air is produced is slightly lower; in the example of Fig. 12 hot air above $800^{\circ} \mathrm{C}$ is produced for $585 \mathrm{~s}$, compared to $610 \mathrm{~s}$ in the base case. The reason for this is that the bed is cooled down more because of the lower syngas temperature.

To confirm and quantify the advantages in terms of plant efficiency of the different options, a detailed energy analysis of the entire IGCC plant with CLC has to be performed. This is outside the scope of the present investigation and will be carried out in a separate work.

\section{Novel approach: two-stage CLC}

At this moment, much research is carried out to find an oxygen carrier that fulfills all the criteria for the CLC process (high oxygen capacity, high temperature rise and reactivity, high chemical and mechanical stability and high selectivity). It turns out to be difficult to find an oxygen carrier that is highly reactive at $450^{\circ} \mathrm{C}$ and that is also mechanically and chemically stable at $1200^{\circ} \mathrm{C}$ and 20 bar (Hossain and de Lasa, 2008). In the previous section, copper oxide was used, but this is not feasible for a single stage CLC process as its melting point is below $1200^{\circ} \mathrm{C}$. Therefore, a two-stage CLC configuration is proposed.

In this two-stage configuration, the heat that is produced in a first bed is transferred to a second bed and there the desired temperature of $1200^{\circ} \mathrm{C}$ is reached. A schematic overview of the axial temperature profiles is depicted in Fig. 13. After heat removal, the temperature in the first bed is equal to the gas inlet temperature of $450^{\circ} \mathrm{C}$ and the second bed has a higher temperature (in this example $857^{\circ} \mathrm{C}$ ), which was previously produced in the first bed. Afterwards, reduction and oxidation reactions are carried out leading to a temperature increase in both beds. Then, the heat is removed again by blowing the hot air of $1200^{\circ} \mathrm{C}$ to the gas turbine and transferring the heat from the first bed to the second bed.

The demands on the oxygen carrier will become lower in the case that the process is carried out in two stages. Smaller temperature differences exist in each reactor, which also makes it less 


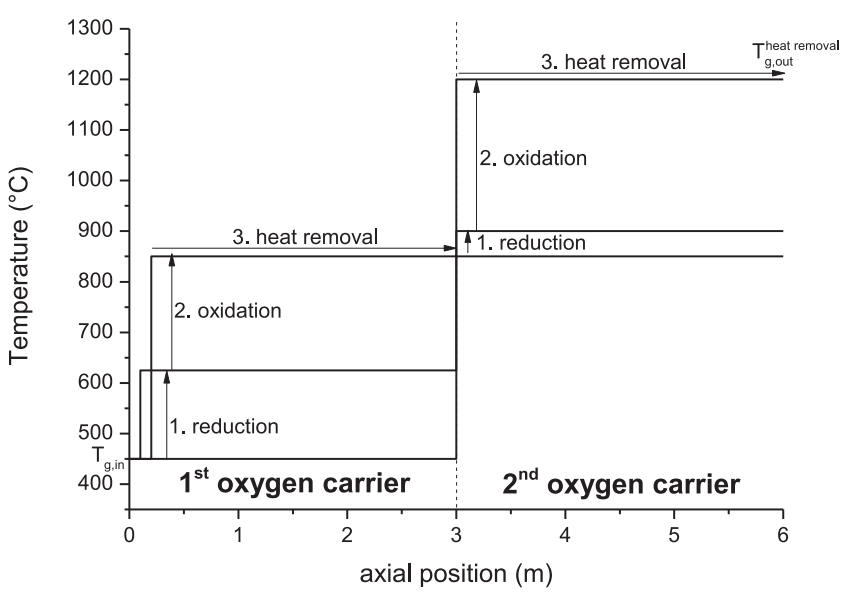

Fig. 13. A schematic overview of the two-stage configuration for CLC in packed beds.

demanding for construction. For this approach, the first bed should contain an oxygen carrier that reacts fast at low temperature (such as Cu-based oxygen carriers). For the second bed, it is important that the carrier (that might be more expensive) is stable at the more challenging process conditions. Because of the high temperature, the kinetics might not be the most important criterion. Moreover, as the temperature rise required in the second bed is not extreme, a low oxygen capacity of the oxygen carrier can also be tolerated.

This novel CLC concept has been explored here by using the 1D model described in Section 3. In this case, $12.5 \mathrm{wt} \% \mathrm{CuO} / \mathrm{Al}_{2} \mathrm{O}_{3}$ is selected for the first bed and $30 \mathrm{wt} \% \mathrm{Mn}_{3} \mathrm{O}_{4} / \mathrm{Al}_{2} \mathrm{O}_{3}$ for the second bed. $\mathrm{CuO} / \mathrm{Al}_{2} \mathrm{O}_{3}$ reacts quite fast even at $450{ }^{\circ} \mathrm{C}$ (García-Labiano et al., 2004), but has a low melting point. Although manganese has a low oxygen carrier capacity-as shown in Table $1,51 \%$ of $\mathrm{Mn}_{3} \mathrm{O}_{4}$ is required to reach a temperature rise of $750^{\circ} \mathrm{C}$-it can be still be used for the second bed in this novel reactor configuration. Of course, other carriers that suffer from slow kinetics at low temperature could be selected for this configuration as well.

In the simulation, two packed beds of $3 \mathrm{~m}$ each are considered. The length of both beds is the same, because the heat front velocities are similar as well. If the heat front velocities would be different (due to differences in $\varepsilon_{s} \rho_{s} C_{p, s}$ ), the bed with the lowest heat capacity should be larger. However, this is also a parameter that could be optimized during the design of an actual reactor. Also, in this case it is assumed that the particle porosities are $60 \%$. The inlet temperature is $450^{\circ} \mathrm{C}$ and the pressure is 20 bar.

The flow rate during the oxidation is set at $4 \mathrm{~kg} /\left(\mathrm{m}^{2} \mathrm{~s}\right)$ to limit the pressure drop to about $1 \mathrm{bar}$. The flow rate during reduction is $0.2 \mathrm{~kg} /\left(\mathrm{m}^{2} \mathrm{~s}\right)$ in order to reach the same cycle time as during oxidation. The selected parameters for this simulation are shown in Table 5.

In this simulation, an outlet temperature profile is obtained as shown in Fig. 14. It is demonstrated that by this configuration, a temperature of $1190^{\circ} \mathrm{C}$ is reached. It takes two cycles before the steady state situation is achieved.

Fig. 15 shows the axial temperature profiles over both beds at different moments in the reduction cycle (Fig. 15a) and oxidation (and heat removal) cycle (Fig. 15b). In this figure, the first three meters represent the first reactor containing $\mathrm{CuO} / \mathrm{Al}_{2} \mathrm{O}_{3}$. From 3 to $6 \mathrm{~m}$ the reactor is filled with $\mathrm{Mn}_{3} \mathrm{O}_{4} / \mathrm{Al}_{2} \mathrm{O}_{3}$. After the oxidation cycle, the first bed is at the air inlet temperature $\left(450^{\circ} \mathrm{C}\right)$ and the second bed is mainly at $857^{\circ} \mathrm{C}$. Between the beds there is a smooth temperature transition due to heat dispersion. At the end of the second bed, there is some remaining heat that cannot be used efficiently during oxidation. During the reduction step, the temperature in the first bed rises because of the exothermic $\mathrm{CuO}$ reduction
Table 5

Defined base case for the dual bed simulation.

\begin{tabular}{|c|c|c|c|c|}
\hline & \multicolumn{2}{|c|}{ BED 1} & \multicolumn{2}{|c|}{ BED 2} \\
\hline Oxygen carrier & \multicolumn{2}{|c|}{$12.5 \mathrm{wt} \% \mathrm{CuO}$ on $\mathrm{Al}_{2} \mathrm{O}_{3}$} & \multicolumn{2}{|c|}{30 wt $\% \mathrm{Mn}_{3} \mathrm{O}_{4}$ on $\mathrm{Al}_{2} \mathrm{O}_{3}$} \\
\hline Particle diameter [mm] & \multicolumn{2}{|c|}{3} & \multicolumn{2}{|c|}{3} \\
\hline $\begin{array}{l}\text { Solids bulk density in } \\
\text { oxidized state, } \varepsilon_{s} \rho_{s} \\
{\left[\mathrm{~kg} / \mathrm{m}^{3}\right]}\end{array}$ & 999 & & \multicolumn{2}{|c|}{1006} \\
\hline Gas porosity & \multicolumn{2}{|l|}{0.4} & \multicolumn{2}{|c|}{0.4} \\
\hline \multirow{2}{*}{ Reactor length [m] } & 3.0 & & \multicolumn{2}{|c|}{3.0} \\
\hline & \multicolumn{2}{|r|}{ Oxidation/heat removal } & Reduction & Purge \\
\hline \multicolumn{2}{|l|}{ Gas inlet flowrate $\left[\mathrm{kg} /\left(\mathrm{m}^{2} \mathrm{~s}\right)\right]$} & 4 & 0.2 & 1 \\
\hline Gas inlet [mol fraction] & & $\mathrm{O}_{2}: 0.21$ & $\begin{array}{l}\mathrm{H}_{2}: 0.5 \\
\mathrm{CO}: 0.5\end{array}$ & $\mathrm{~N}_{2}: 1$ \\
\hline Gas inlet temperature $\left[{ }^{\circ} \mathrm{C}\right]$ & & 450 & 450 & 450 \\
\hline Gas inlet pressure [bar] & & 20 & 20 & 20 \\
\hline $\begin{array}{l}\text { Reaction rate, } r_{i} \\
{\left[\mathrm{~mol} /\left(\mathrm{m}^{3} \mathrm{~s}\right)\right]}\end{array}$ & & $50 \mathrm{c}_{\mathrm{O}_{2}}$ & $\begin{array}{l}25 c_{\mathrm{H}_{2}} \\
25 c_{\mathrm{CO}}\end{array}$ & - \\
\hline Cycle time [s] & & 690 & 640 & 10 \\
\hline
\end{tabular}

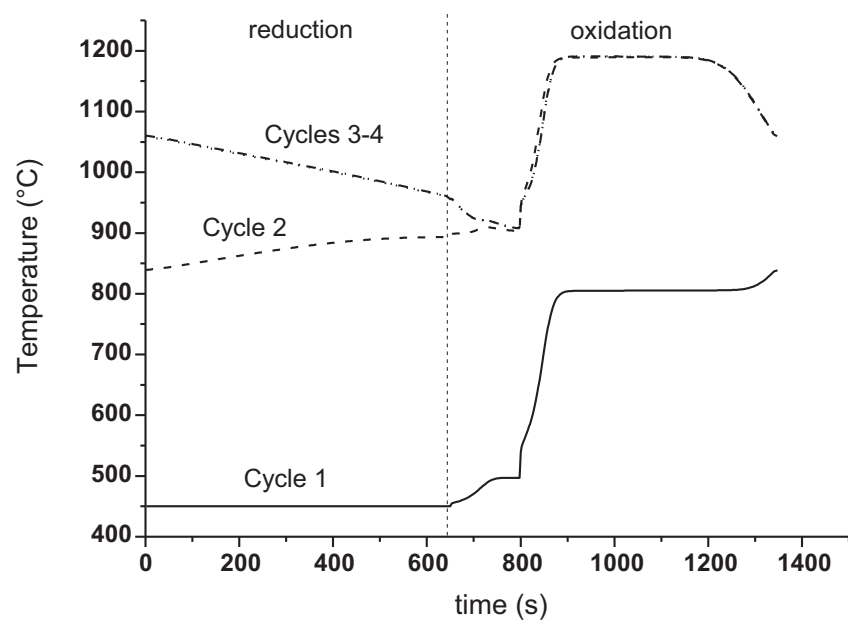

Fig. 14. The outlet temperature of the two-stage configuration.

reaction. In the second bed, a smaller temperature rise is observed because the $\mathrm{Mn}_{3} \mathrm{O}_{4}$ reduction reaction is less exothermic.

During oxidation, the first bed is oxidized in about $80 \mathrm{~s}$. After $150 \mathrm{~s}$, both beds are oxidized and hot air is produced at $1190^{\circ} \mathrm{C}$. In total, hot air (with $T>1150^{\circ} \mathrm{C}$ ) is produced for $404 \mathrm{~s}$; this means that $61 \%$ of the fuel energy is converted into hot air. The remaining energy is obtained at a lower temperature (which can still be used, but a more detailed energy analysis is required). Initially, the oxidation cycle starts with a dispersed bed and during the cycle itself, more dispersion occurs. The extent of dispersion also becomes clear when the actual axial temperature profiles in Fig. 15 are compared with the ideal case (scheme in Fig. 13). Due to this effect, a more dispersed outlet temperature profile is obtained in comparison with the single stage configuration. However, the process becomes less demanding regarding the oxygen carrier properties.

With these results, it is demonstrated that the two-stage configuration can be used to achieve the desired temperature rise $\left(450-1200^{\circ} \mathrm{C}\right.$ ) and avoid fuel slip (because of high reactivity of the first oxygen carrier at low temperature) while it is less demanding regarding the oxygen carrier properties and the reactor construction and still uses relatively cheap oxygen carriers. This concept has been theoretically demonstrated for syngas as the fuel, but is also applicable in case methane is used. 

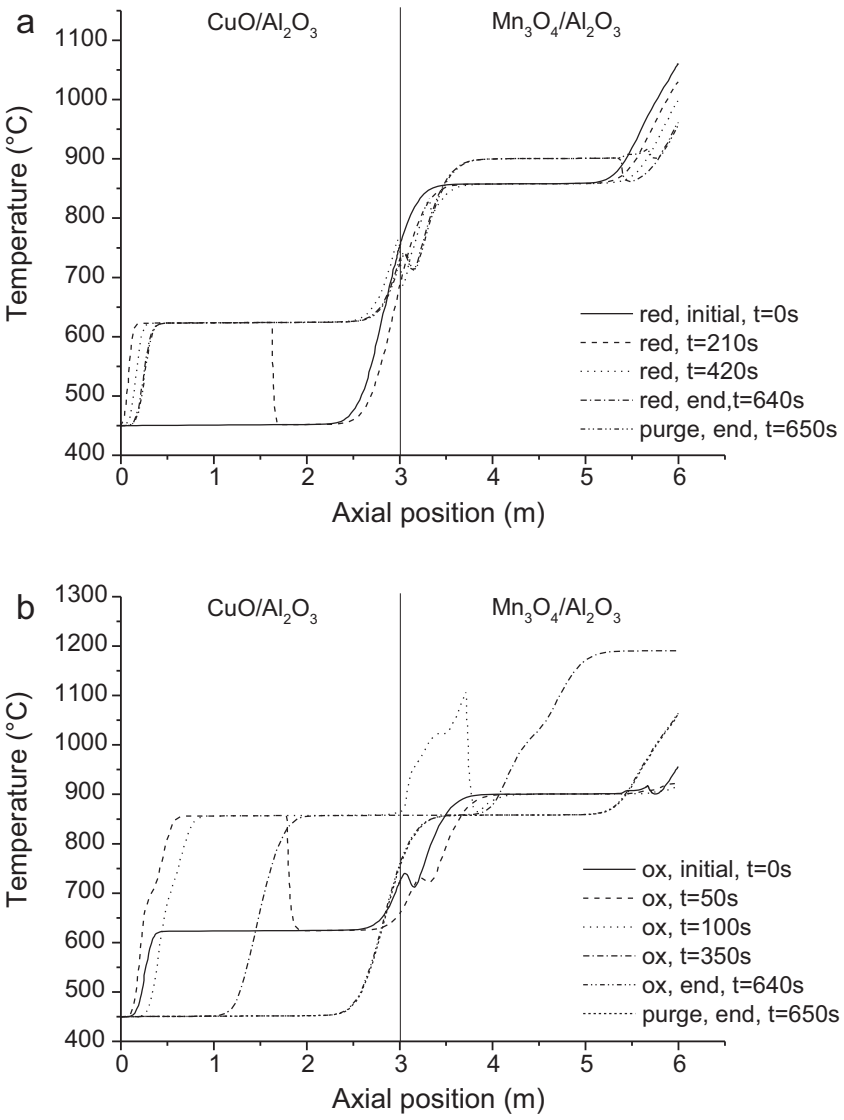

Fig. 15. The axial temperature profiles during the reduction (a) and oxidation/heat removal (b) cycles of the two-stage configuration.

\section{Discussion and conclusions}

This work describes the use of syngas as a fuel in chemical looping combustion carried out in dynamically operated packed beds.

First, the effect of using syngas as the fuel on the characteristics of the CLC operation (temperature and concentration profiles) has been examined. From a thermodynamic point of view, CLC with syngas as the fuel is possible with the four most studied oxygen carriers: nickel, copper, iron and manganese. The reduction reactions are mostly exothermic. With $\mathrm{CuO}$, a temperature of $1200^{\circ} \mathrm{C}$ (the target for higher process efficiency) cannot be reached in a single stage system, because of the low melting point of copper. The temperature rise cannot be achieved with an iron carrier when only the reaction from $\mathrm{Fe}_{2} \mathrm{O}_{3}$ to $\mathrm{Fe}_{3} \mathrm{O}_{4}$ is considered. However, $\mathrm{Fe}_{3} \mathrm{O}_{4}$ cannot be further reduced, because then the selectivity will drop to undesired values. Nickel could be a good carrier, but is toxic and expensive. For manganese based oxygen carriers, a high manganese content is required to reach a $750^{\circ} \mathrm{C}$ temperature rise during oxidation, making it difficult to assure mechanical stability.

By simulating the CLC operation with a $1 \mathrm{D}$ reactor model, the evolution of the axial concentration and temperature profiles in the reactor have been investigated. It was shown that after 2 or 3 cycles with repeated oxidation and reduction reactions, a cyclic steady state situation is reached. In this stage, hot air is produced at a constant temperature. The process efficiency can be improved by feeding the syngas from the counter-current direction. However, heat remaining from the previous cycle is accumulated at one position (hot spot formation). This results in a temperature peak in the outlet temperature profile, which is not beneficial for the gas turbine performance.
It has been proven that the CLC process can also be carried out in a two-stage configuration. This concept has the advantage that the oxygen carrier selection becomes less critical, because smaller temperature differences prevail in one reactor. In this configuration, an air outlet stream at $1200^{\circ} \mathrm{C}$ and 20 bar has been produced. However, the heat dispersion is somewhat increased in this two-stage concept, lowering the overall energy efficiency. In future work, a detailed energy analysis involving the two stage process will be carried out in order to quantify the advantages/disadvantages of the novel process configuration. The two-stage approach might increase the feasibility of the packed bed CLC process, because in this configuration large temperature differences do not occur within one reactor and more oxygen carriers can be selected that fulfill all the requirements.

\section{Acknowledgments}

The research originating these results has been supported by the Dutch National Program CATO-2 under the project number WP1.3F2.

\section{References}

Adanez, J., Abad, A., Garcia-Labiano, F., Gayan, P., de Diego, L.F., 2012. Progress in chemical-looping combustion and reforming technologies. Progress in Energy and Combustion Science 38, 215-282.

Barin, I., 1993. Thermochemical Data of Pure Substances. VCH, Weinheim.

Cho, P., Mattisson, T., Lyngfelt, A., 2005. Carbon formation on nickel and iron oxide-containing oxygen carriers for chemical-looping combustion. Industrial \& Engineering Chemistry Research 44, 668-676.

Daubert, T.E., Danner, R.P., 1985. Data Compilation Tables of Properties of Pure Compounds. American Institute of Chemical Engineers, New York.

Forero, C.R., Gayán, P., de Diego, L.F., Abad, A., García-Labiano, F., Adánez, J., 2009. Syngas combustion in a 500-Wth chemical-looping combustion system using an impregnated Cu-based oxygen carrier. Fuel Processing Technology 90, 1471-1479.

García-Labiano, F., de Diego, L.F., Adínez, J., Abad, A., Gayán, P., 2004. Reduction and oxidation kinetics of a copper-based oxygen carrier prepared by impregnation for chemical-looping combustion. Industrial \& Engineering Chemistry Research 43, 8168-8177.

Hamers, H.P., Gallucci, F., Cobden, P.D., Kimball, E., van Sint Annaland, M. CLC in packed beds using syngas and $\mathrm{CuO} / \mathrm{Al}_{2} \mathrm{O}_{3}$ : model description and experimental validation, submitted for publication to applied energy.

Hossain, M.M., de Lasa, H.I., 2007. Reactivity and stability of $\mathrm{Co}-\mathrm{Ni} / \mathrm{Al}_{2} \mathrm{O}_{3}$ oxygen carrier in multicycle CLC. AIChE Journal 53 (7), 1817-1829.

Hossain, M.M., de Lasa, H.I., 2008. Chemical-looping combustion (CLC) for inherent $\mathrm{CO}_{2}$ separations-a review. Chemical Engineering Science 63, 4433-4451.

Hossain, M.M., Lopez, D., Herrera, J., de Lasa, H.I., 2009. Nickel on lanthanummodified $\gamma-\mathrm{Al}_{2} \mathrm{O}_{3}$ oxygen carrier for CLC: reactivity and stability. Catalysis Today $143(1-2), 179-186$.

IPCC, 2005. In: Metz, B., Davidson, O., de Coninck, H., Loos, M., Meyer, L. (Eds.), IPCC Special Report on Carbon Dioxide Capture and Storage. Cambridge University Press, New York.

Jerndal, E., Mattisson, T., Lyngfelt, A., 2006. Thermal analysis of chemical-looping combustion. Chemical Engineering Research and Design 84, 795-806.

Kolbitsch, P., Bolhàr-Nordenkampf, J., Pröll, T., Hofbauer, H., 2010. Operating experience with chemical looping combustion in a $120 \mathrm{~kW}$ dual circulating fluidized bed (DCFB) unit. International Journal of Greenhouse Gas Control 4, $180-185$.

Linderholm, C., Abad, A., Mattisson, T., Lyngfelt, A., 2008. $160 \mathrm{~h}$ of chemical-looping combustion in a $10 \mathrm{~kW}$ reactor system with a NiO-based oxygen carrier. International Journal of Greenhouse Gas Control 2, 520-530.

Lyngfelt, A., 2011a. Communication During ICEPE 2011 Conference (Frankfurt) Presentation.

Lyngfelt, A., 2011b. Oxygen carriers for chemical looping combustion - $4000 \mathrm{~h}$ of operational experience. Oil \& Gas Science and Technology - Revue D Ifp Energies Nouvelles 66, 161-172.

Mattisson, T., Lyngfelt, A., Leion, H., 2009. Chemical-looping with oxygen uncoupling for combustion of solid fuels. International Journal of Greenhouse Gas Control 3, 11-19.

Noorman, S., van Sint Annaland, M., Kuipers, J.A.M., 2010. Experimental validation of packed bed chemical-looping combustion. Chemical Engineering Science 65, 92-97.

Noorman, S., van Sint Annaland, M., Kuipers, 2007. Packed bed reactor technology for chemical-looping combustion. Industrial \& Engineering Chemistry Research 46, 4212-4220.

Sedor, K.E., Hossain, M.M., de Lasa, H.I., 2008. Reactivity and stability of $\mathrm{Ni} / \mathrm{Al}_{2} \mathrm{O}_{3}$ oxygen carrier for chemical-looping combustion (CLC). Chemical Engineering Science 63 (11), 2994-3007. 
Smit, J., van Sint Annaland, M., Kuipers, J.A.M., 2005. Grid adaptation with WENO schemes for non-uniform grids to solve convection-dominated partial differential equations. Chemical Engineering Science 60, 2609-2619.

Spallina, V., Gallucci, F., Romano, M.C., Chiesa, P., Lozza, G., Van Sint Annaland, M. 2013. Investigation of heat management for CLC technology with syngas for packed bed reactors integration in coal power plants. Chemical Engineering Science, http://dx.doi.org/10.1016/j.cej.2013.03.054.

Wolf, J., Anheden, M., Yan, J., 2005. Comparison of nickel- and iron-based oxygen carriers in chemical looping combustion for $\mathrm{CO}_{2}$ capture in power generation. Fuel 84, 993-1006. 
